\title{
Study on the Application of O2O Mode in the Development of Garment Enterprises in Jilin Province
}

\author{
Jiaxin Zhang ${ }^{1, a^{*}}$ \\ 1.Jilin Engineering Normal University, Changchun,China,130052 \\ a1060138576@qq.com,
}

Keywords: O2O; Enterprise development; Mobile e-commerce; Clothing brand; Business model

\begin{abstract}
In recent years, with the rise of e-commerce, many local brands clothing enterprises operating dismal, revenue is declining, especially the entity clothing store is facing high inventory, high cost problems. How to look for the next round of breakthroughs? Many clothing enterprises have turned their attention to $\mathrm{O} 2 \mathrm{O}$. The practice of $\mathrm{O} 2 \mathrm{O}$ mode makes garment enterprises get good transformation, but they will face many problems in the process of implementation. The current retail clothing business compared to typical $\mathrm{O} 2 \mathrm{O}$ mode including store mode, private custom mode, store mode and mode of 4 kinds of fans, these 4 models have advantages and disadvantages respectively, clothing retailer $\mathrm{O} 2 \mathrm{O}$ smoothly from the depth of integration of supply chain and improve the line store experience, the adjustment of the organizational structure, personnel training of $\mathrm{O} 2 \mathrm{O}$ and some other aspects. This article from the concept of $\mathrm{O} 2 \mathrm{O}$, the garment enterprises to implement $\mathrm{O} 2 \mathrm{O}$ and the typical patterns of the difficulties and solve several aspects of the strategy to explore that brand clothing enterprises can according to their own circumstances to try to achieve sales breakthrough flexible.
\end{abstract}

\section{Preface}

The clothing category in the channel network selling not only promote the traditional clothing enterprises "electric shock", also intensified the competition between the clothing enterprises, network clothing brand to enhance the brand visibility and influence, began the trial under the waterline store management, diversified product sales model clothing upgrade, pay more attention to the integration of Online and offline store sales platform the. With the rising number of mobile phone users in China and a sharp rise in the mobile phone shopping, mobile e-commerce and garment industry $\mathrm{O} 2 \mathrm{O}$ has become a new profit growth point, how to combine online and offline business opportunities, to promote product sales space by $\mathrm{O} 2 \mathrm{O}$, has become the focus of attention of the clothing enterprise.

\section{Clothing Retail Enterprise O2O Connotation and Present Situation}

Brief Introduction of O2O. O2O is the abbreviation of Offline Online to, refers to the line of business opportunity combined with the Internet, purchase operations led by the line and line through online marketing, online consumption, the definition of $\mathrm{O} 2 \mathrm{O}$ is broader in the actual operation process, as long as the industry chain involved in online and offline, can be called O2O. Group buying is an application of the early $\mathrm{O} 2 \mathrm{O}$ model, in recent years, combined with mobile devices and location-based services, $\mathrm{O} 2 \mathrm{O}$ business model is more inclined to meet localization consumer demand. Download the APP client mode by scanning the two-dimensional code, one can be offline marketing discount and booking service information pushed to Internet users, and guide them to the online shop to complete the transaction, on the other hand through the line store experience to customers to online drainage sale platform online payment to complete the purchase, integration online and offline business opportunity. $\mathrm{O} 2 \mathrm{O}$ model of online information and offline experience integration, making the line consumers from information asymmetry caused by the price deception, and help the online consumer "pre experience", especially for clothing this kind of experience goods, with O2O mode, 
online consumers can enter the next line store experience, personally selected try on the line after the purchase, to avoid because of color and number of codes are not standard caused by the return rate is high, low consumer satisfaction.

Clothing Retail Enterprise O2O Connotation. O2O is built on top of the mobile Internet, and combined with the popularity of mobile positioning, two-dimensional code scanning, mobile payment, maps and search technology depends on the broadband and $\mathrm{WiFi}$, realized the essence of $\mathrm{O} 2 \mathrm{O}$ channels and content fragmentation, line scan two-dimensional code, mobile terminal and network search goods, experience the next line, the online payment transactions, the Internet is no longer the only access to information, online merchandise is not only content. But the $\mathrm{O} 2 \mathrm{O}$ does not change the nature of retail, retail and basic elements of the link of information flow, capital flow, business flow, logistics has not changed, $\mathrm{O} 2 \mathrm{O}$ just realize the whole channel layout, fully open information, goods and payment link online and offline, online virtual experience will become a reality scene.

$\mathrm{O} 2 \mathrm{O}$ will be able to experience the virtual clothing virtual fitting room and 3D display fitting, collocation into reality, can provide online and offline synchronization parity, consumers fitting appointment and personalized customized services, clothing retailer $\mathrm{O} 2 \mathrm{O}$ means that consumers can choose goods orders through the online sales platform, the next line store to try to pick up, or first the online store experience to try, through the mobile electronic equipment line selection and collocation of single payment, $\mathrm{O} 2 \mathrm{O}$ mode combines online stores and online shop advantage, improve consumers' personal experience but also effectively solves the shortcomings of traditional shop goods. Clothing retailer $\mathrm{O} 2 \mathrm{O}$ change, change the line and the line of hostilities in the traditional business environment, not only opened up a new way of clothing business enterprise sales of the line, more importantly, provides a new opportunity for the development of the electricity supplier has not yet transition or transformation is not ideal in traditional clothing retail enterprises.

At present, the operation of clothing $\mathrm{O} 2 \mathrm{O}$ is under the line of old customers drain to the line, increasing the number of usual consumption; or to attract online new customers online or online consumption. It is understood that, at present, there is no real success of the clothing company $\mathrm{O} 2 \mathrm{O}$, did not do from the line to the line, or from the line to the line drainage sales.

\section{The Difference between $\mathrm{O} 2 \mathrm{O}$ and $\mathrm{B} 2 \mathrm{C}$}

First of all, the real $\mathrm{O} 2 \mathrm{O}$ should be based on the store itself, both online and offline, online and offline should be an organic integration of the whole interconnected information exchange, resource sharing, online and offline interaction, rather than "from Online to Offline", also is not simple "from the line online". O2O should serve all entities, businesses, and not just limited to food, entertainment and other types; secondly, $\mathrm{O} 2 \mathrm{O}$ should involve the mainstream goods of the entity merchant, and not just a special bargain. Most importantly, for the entity merchant, the Internet is just a tool for it. Any method of putting the cart before the horse will shake the foundation of the development of the real business.

$\mathrm{O} 2 \mathrm{O}$ and $\mathrm{B} 2 \mathrm{C}$ are both forms of service. If from the perspective of consumption to the retail service, then, is the maximum range of retail, including a variety of traditional retail formats (such as supermarket, supermarket, convenience stores, shops, stores, shops and cross classification category;, such as chain stores, and shopping center etc.); from the early retail service methods: can store sales, non store sales (including TV, telephone directory, Internet, etc.).

$\mathrm{O} 2 \mathrm{O}$ is different from $\mathrm{B} 2 \mathrm{C}$ :

One, $\mathrm{O} 2 \mathrm{O}$ more emphasis on service consumption (including catering, movies, beauty, SPA, travel, fitness, car rental, rental housing, etc.); B2C more emphasis on shopping (physical goods, such as appliances, clothing and so on);

Two, $\mathrm{O} 2 \mathrm{O}$ consumers to the scene to obtain services, involving passenger flow; $\mathrm{B} 2 \mathrm{C}$ consumers stay in the office or home, and other door-to-door, involving logistics;

Three, $\mathrm{O} 2 \mathrm{O}$ inventory is the service, $\mathrm{B} 2 \mathrm{C}$ inventory is merchandise;

$\mathrm{O} 2 \mathrm{O}$ and $\mathrm{B} 2 \mathrm{C}$ are the same: 
I. The first interaction between consumers and service providers on the Internet (especially mobile phones);

Two, the main process is closed, and are online, such as online payment, customer service and so on;

Three, demand forecasting management in the background, supply chain management is the core of the success of $\mathrm{O} 2 \mathrm{O}$ and $\mathrm{B} 2 \mathrm{C}$.

\section{Jilin Existing Garment Retail Enterprise O2O Model}

According to the 2013 Jilin Province clothing performance report, a number of garment enterprises have appeared to decline in net profit, several garment enterprises have expressed high inventory of frustration, channel inventory pressure intensifies, retail competition intensified, retail discount increased, so that the terminal retail profit margins to decline further. As an emerging business model, the $\mathrm{O} 2 \mathrm{O}$ of clothing retail enterprises is still in the stage of practical exploration, and different enterprises have different emphases on $\mathrm{O} 2 \mathrm{O}$ layout.

Jilin province traditional clothing store operation pain points: line line separation, high operating costs; "sellers show" and "buyers show" big contrast; online users can not provide products on display and store; operation time; cycle mode of industry chain is long, the cost onto consumers; large backlog of inventory, cash flow difficulties the line of stores; high rental costs, the enterprise input-output ratio is low; overcapacity, oversupply, a large number of stores closed shop closed.

The clothing industry of the storm, not only because the retail terminal discounts can be solved, Chinese population, a large amount of online shopping, in the rapid development of electronic commerce case, how to use the new $\mathrm{O} 2 \mathrm{O}$ mode, online and offline consumption combined, the development of local brands in Jilin Province, has great significance for the development of the clothing industry of our province.

\section{Comparative Analysis Of Existing O2O Models}

The store model relies on the exchange of their influence brand driven offline and online users, in store merchandise and promotional information of the two-dimensional code scanning and mobile APP client to download the initiative in the hands of users, the key exchange line is their own brand appeal and customer loyalty.

Personal customization will store in a shopping guide mode and the mobile terminal customers through the essence lies in the mobile terminal customers to the shop to buy drainage experience, but the customer contact guide, make an appointment to the shop in the process design of intangible increased customer mobile shopping time and the whole experience is more complicated.

Store mode manual service and high-tech services combined, not only to provide advice on a collocation fashion consultant for customers, provide convenience for customers to see all kinds of electronic screen computer for a piece of clothing with collocation suggestions, at the same time, Dan Pinxin also suggested the collocation information will be displayed on the screen, convenient shopping search, this model for the next line will lead to customers online has certain effect, but the online and offline exchange also has some shortcomings, in addition, store related equipment and space into life experience, certainly will increase the cost of business entity shop.

Fans use pattern of social marketing and fan interactive word-of-mouth marketing function, the line will guide customers to buy online, improve the online shop CTR and brand exposure, but should pay attention to the line of products of different models in the implementation process, as a result of or with different price of the shop and the store Bo situation. Especially for the agent and joined the mechanism of clothing enterprises, the use of fan mode need more careful. 


\section{Clothing Retail Enterprises to Carry out Specific Recommendations O2O}

$\mathrm{O} 2 \mathrm{O}$ mode of consumption processes can be divided into 5 stages of diversion, transformation, consumption, feedback and retention, although many domestic apparel retail enterprises are actively exploring $\mathrm{O} 2 \mathrm{O}$ mode, but most remain in the primary stage of diversion, realize the transformation of consumers and the order is not much, the consumer experience feedback and retention is less and less. Combined with the current domestic and international clothing retail enterprise $\mathrm{O} 2 \mathrm{O}$ related cases, it is recommended to start with the following aspects.

Beautiful and comfortable shopping environment, a clear and open display of goods distribution, free $\mathrm{WiFi}$ and location search technology, friendly interface and APP customer relationship management system, flexible and convenient purchase payment process, warm and professional shopping guide, customers are able to advance to a certain extent experience. The $\mathrm{O} 2 \mathrm{O}$ mode is not only a place to store merchandise display and sales, is showing the brand culture and life style of the platform, should be combined with different regions and values of the consumption habits, customs, age and occupation structure set up different scenarios, more targeted to meet the needs of subdivision consumer groups.

\section{Adjust the Organizational Structure}

The smooth progress of $\mathrm{O} 2 \mathrm{O}$ depends on the profound change of consciousness, and the management needs to use the Internet thinking to adjust the existing organizational structure of the enterprise, and adapt to the management mode and operation thinking of the two sets of online and offline systems. In order to realize the data fusion of online and offline and the inventory allocation, clothing retail enterprises need to set up the new high order management, store, sales network platform and mobile terminal price strategy and goods management under the overall planning, coordination is responsible for the channel information of all goods, all kinds of marketing activities in the integration of online and offline and the mobile terminal.

\section{Summary}

Future enterprises may not exist purely online or offline has gradually become a consensus, changing consumer shopping habits based on clothing line retail business must face up to the Internet and e-commerce brings to the traditional garment industry changes, network clothing brand also need to enhance the brand influence through integration and multi business, the integration of online and offline is represent the general trend. In the mobile Internet boom, the rapid transfer of PC terminal network applied to the mobile terminal, the mobile terminal also actively to convert $\mathrm{O} 2 \mathrm{O}$ PC end $\mathrm{B} 2 \mathrm{C}$ mode of retail clothing business, the line will be as the basis of user experience and interaction, but the true sense of the $\mathrm{O} 2 \mathrm{O}$ requires the integration of the supply chain in depth, will be great test of the operating capacity of the enterprise, the clothing retail enterprises want to do $\mathrm{O} 2 \mathrm{O}$, also need to combine their own characteristics of continuous exploration in practice.

\section{Reference}

[1] Li Lili. Discussion on brand clothing, electricity supplier enterprise operation and marketing strategy -- Take Korean clothing house as an example, [J]. textile Herald, 2014.

[2] Jiang Li, Ding O2O business model perspective and its thick Chun. Mobile marketing strategy of [J]. business era, 2014.

[3], Fan Fujun, Chen Changzu, Chen Fangming. E-commerce transformation model for small and medium garment enterprises [J]. Textile journal, 2014.

[4] Wu Zhi. O2O breakthrough of clothing brand [J]. China textile, 2014. 